\title{
Classification of temporomandibular joint sounds based upon their reduced interference distribution
}

\author{
S.E. WIDMALM, * W.J. WILLIAMS ${ }^{\dagger}$ R.L. CHRISTIANSEN, ${ }^{\ddagger}$ S.M. GUNN $\mathcal{E}^{\prime}$ \\ D.K. P A R K ${ }^{\ddagger}{ }^{*}$ Department of Biologic \& Materials Sciences, ${ }^{+}$Department of Electrical Engineering and Computer \\ Science and ${ }^{\ddagger}$ Department of Orthodontics and Pediatric Dentistry, University of Michigan, Ann Arbor, MI, U.S.A.
}

SUMMARY Temporomandibular joint (TMJ) sounds were recorded in 98 orthodontic retention patients, mean age $19 \pm 8.6$ (s.d.) years, by interview, auscultation and electronic recording. Sounds were found by auscultation in $41 \%$ and by interview in $32 \%$ of the subjects, more often in females than in males $(P<0.05)$. A new method for time-frequency analysis, the reduced interference distribution (RID), was used to classify the electronic sound recordings into five subclasses, RID types 1-5, based upon location and number of their energy peaks. RID types 1-3 had a few energy peaks close in time. RID types 4-5, typical of subjects with crepitation, had multiple energy peaks occurring close in time for a period of 20$300 \mathrm{~ms}$. RID type 1, found in $45 \%$ of the subjects, typical of patients with clicking, had its dominant energy peak located in a frequency range $<600 \mathrm{~Hz}$ and was significantly more common in the female than in the male subjects $(P<0.01)$. RID type 2 , found in $68 \%$ of the subjects, with the dominant peak in the range $600-1200 \mathrm{~Hz}$, and RID type 3, found in $38 \%$ of the subjects, with the peak in the frequency range $>1200 \mathrm{~Hz}$, were found to have a similar gender distribution. RID type 4 , found in $49 \%$ of the subjects, had the energy peaks distributed in the frequency range $<600 \mathrm{~Hz}$. RID type 5 , found in $43 \%$ of the subjects, more often in females than in males $(P<0.05)$, had the peaks distributed over the whole frequency range from about $30 \mathrm{~Hz}$ up to about $3000 \mathrm{~Hz}$. In conclusion, a more detailed classification could be made of the TMJ sounds by displaying the RIDs than by auscultation. This suggests that RID classification methods may provide a means for differentiating sounds indicating different types of pathology.

\section{Introduction}

Sounds evoked in joints during motion may indicate pathology (Farrar, 1972; Isberg-Holm \& Westesson, 1982 a, b; Eriksson, Westesson \& Rohlin, 1985; Widmalm et al., 1992; Katzberg \& Westesson, 1993; Michet \& Hunder, 1993). Temporomandibular joint (TMJ) sounds, clicking and crepitation are generally classified according to their loudness, character, and to their location during the joint movement. The word clicking is generally used to describe a single, slight, sharp sound. Crepitation or crackling is a series of sudden sharp rapidly repeated noises that occur close in time, presumably when roughened articular surfaces are rubbed against each other (Watt, 1963, 1980; Farrar \& McCarty, 1983). A distinction is sometimes made in clinical auscultation between fine and course crepitation and those two types of joint sounds are supposed to indicate different stages or types of pathology. Bone-on-bone crepitus has been observed to produce a higher frequency 'squeak'. Crepitation is routinely recorded in patients with suspected rheumatologic joint diseases (Michet \& Hunder, 1993).

Recording of TMJ sounds is being widely used by dental practitioners, but its clinical value is still a controversial question (Mohl et al., 1990). Females are known to seek treatment for TM disorders (TMD) more often than males (Helkimo, 1979). The prevalence of TMJ sounds in females as compared with males is, therefore, of interest. Some studies have shown a higher prevalence of TMJ sounds in females than in males (Egermark-Eriksson, 1982; Wänman 
\& Agerberg, 1990; Widmalm et al., 1995), others have not found any difference (Helkimo, 1979; Wedel, 1988).

A main obstacle in relating sounds to pathology is the difficulty in making accurate comparisons between observations by different observers based upon auscultation and verbal descriptions of the sounds (Eriksson, Westesson \& Sjöberg, 1987; Dworkin et al., 1990). New methods for electronic sound recording and for analysis of the sounds by displaying their time-frequency distribution (Ouellette, 1974; Heffez \& Blaustein, 1986; Widmalm, Williams \& Zheng, 1991) offer promising alternatives to the old clinical methods. Several methods for electronic recording and analysis of TMJ sounds have been described during the last decades (Ekensten, 1952; Widmalm \& Hedegård, 1974; Watt, 1980; Drum \& Litt, 1987; Ishigaki, Bessette \& Maruyama, 1993). Spectral analysis of electronically recorded sounds is a promising alternative even if general consensus has not yet been reached (Gay \& Bertolami, 1987; Mohl et al., 1990; Christensen, Donegan \& McCay, 1992). An important obstacle is the difficulty to distinguish, between artefacts, naturally occurring biological sounds and sounds that indicate pathology (Widmer, 1989). The technology for displaying joint sound recordings has, however, recently been improved by a technique where the time-frequency distribution of the sound can be displayed as a three-dimensional graph (RID) with more details and fewer artefacts than in earlier techniques (Widmalm et al., 1991, Williams \& Jeong, 1992).

The null hypotheses of the present study were: there are no gender differences in prevalence of TMJ sounds; there is no added value in using the reduced interference distribution (RID) at classification of TMJ sounds; there is no association between types of RID and types of TMJ sounds as recorded by auscultation. The aims of the present study were: to compare the prevalence of TMJ sounds, as recorded by interview, auscultation and electronic recording, in young females and males from a non-patient population; to use the newly developed method for time-frequency analysis, the reduced interference distribution (RDD), to classify the electronically recorded TMJ sounds and; to compare classification based on the sound's time-frequency distribution to conventional classification of TMJ sounds by auscultation.

\section{Materials and methods}

\section{Subjects}

The group consisted of 98 subjects, 59 orthodontic retention patients with treated malocclusion and 39 subjects with malocclusion not yet treated. None of the subjects were being treated, or seeking treatment, for TMJ pain or dysfunction. There were 38 males, mean age $18 \cdot 7 \pm 7 \cdot 00$ (s.d.) years and 60 female subjects, mean age 19.7 \pm 9.48 (s.d.). There were no significant differences in mean age or age distribution between the females and the males.

The following figures regarding occlusion, prevalence of oral parafunctions and of TMD signs and symptoms are given to facilitate comparisons between the subjects in this study and other populations. The distribution of malocclusion was Class I $34 \cdot 4 \%$, Class II $54 \cdot 1 \%$, Class III $11.5 \%$. Regarding oral parafunctions $37.6 \%$ did bite or had been biting their fingernails, $29.0 \%$ had a history of thumb or finger sucking, and $23.4 \%$ were aware of a bruxing habit. The prevalence figures for signs and symptoms related to TMJ pain and dysfunction were: pain at chewing $(24.5 \%)$, recurrent (>once/week) headache $(21.5 \%)$, recurrent neckpain $(12.9 \%)$, palpation soreness in the left and/or right posterior TMJ area (9.9\%), palpation soreness in the anterior left and/or right temporal area $(7 \cdot 7 \%)$, palpation soreness in the lateral left and/or right TMJ area $(7 \cdot 7 \%)$, difficulties in opening the mouth $(7.5 \%)$, pain at jaw opening $(6.5 \%)$, palpation soreness in the left and/or right masseter area (5.5\%), less than $40 \mathrm{~mm}$ jaw opening ability $(4 \cdot 3 \%)$, recurrent earache $(2 \cdot 2 \%)$. Only two subjects had more than mild soreness or pain at palpation as judged by observing the palpebral reflex. One subject had locking in the past.

\section{Sound recording}

Interview and auscultation. Each subject was asked the question: 'When you open your mouth, do you have any noises by your ears?' The examiner also used a stethoscope to listen for TMJ sounds during jaw movements. Sounds during opening, closing or lateral jaw movements were recorded as clicking, a slight sharp sound, or crepitation, a series of sudden sharp rapidly repeated noises. Sounds occurring at maximal jaw opening, when the condylar head passed the apex of the articular eminence, were not noted.

\section{Electronic recording}

Piezoelectric accelerometers*, that measure the rate at which the velocity of the vibrating tissues are changing their acceleration, were used to record the sounds. The

* Model 207A, Bioresearch, Milwaukee, WI, U.S.A. 
accelerometers were calibrated before the experiments. They had a resonant frequency at $3800 \mathrm{~Hz}$ and a flat response between 20 and $3600 \mathrm{~Hz}$. The accelerorneters were fastened over the lateral aspects of the TM joints and held in place by a spring holder. Double-stick tape was used to prevent the accelerometers from sliding against the skin during recording.

The sounds were amplified with a low frequency cutoff at $32 \mathrm{~Hz}$ and the high frequency anti-aliasing cutoff at $3200 \mathrm{~Hz}$ (TECA TE42 system, with AA6 Mk.III amplifiers $)^{*}$. The signals were digitized with a sampling rate of $7200 \mathrm{~Hz}$. A high speed adjustable gain analogue/digital I/O expansion board ${ }^{\dagger}$ with an industry standard HI-674A successive approximation converter with $12 \mu \mathrm{s}$ conversion time was used for digitization of the recorded sound signal. Resolution was 12 bits (4096) steps). According to the manufacturer accuracy was $0.01 \%$ of reading \pm 1 bit. Each session started with one recording made during mandibular rest. If the noise level was normal (about $10 \mu \mathrm{V}$ peak to peak), recordings were then made during six habitual maximal opening and closing movements. The analogue wave forms were displayed immediately on the PC monitor after each opening-closing cycle to check that adequate gain was used.

Time-frequency $(t-f)$ representation of signals. The digitized analogue data were transformed from the time domain to the $\mathrm{t}-\mathrm{f}$ domain and displayed as three-dimensional reduced interference (RID) graphs (Widmalm et al., 1991). The input file was a single array of data and the output file was a $128 \times 64$ time-frequency representation matrix. The maximal number of input samples that could be processed at a time was 8192 .

Classification of the reduced interference graphs (RID). The electronic sound recordings were classified into two main groups with subclasses according to number and location of energy peaks. The first group (RID types 1-3) had mostly one single peak (Fig. 1). Sometimes a few (2-3) peaks, close in time, were observed (Fig. 2a). The second group (RID types 4-5) had multiple energy peaks distributed over a longer time period. Those from the first group with the dominant peak in a frequency range $<600 \mathrm{~Hz}$ were designated RID type 1 (Fig. 1). Those with the peak in the range $600-1200 \mathrm{~Hz}$ were designated RID type 2 (Fig. 2a), and those with the peak above $1200 \mathrm{~Hz}$ were called RID type 3 (Fig. 2b \& c). The types of sounds with multiple energy peaks were designated RID type 4 (Fig. 3) and RID type 5 (Fig. 4). The designation RID type 4 was chosen when the peaks were in a frequency range $<600 \mathrm{~Hz}$ and the designation RID type 5 was used when peaks were found also in the range $600-3600 \mathrm{~Hz}$ (Table 1).

Fig. 1. RID (reduced interference distribution) type 1 clicking with the energy peak in a low frequency range $(50-100 \mathrm{~Hz})$. This sound pattern indicates a sudden impact of the condyle onto the disk and/or fossa at sliding over the posterior thick band or the impact on the fossa when the condyle is sliding over the edge of a disc perforation.

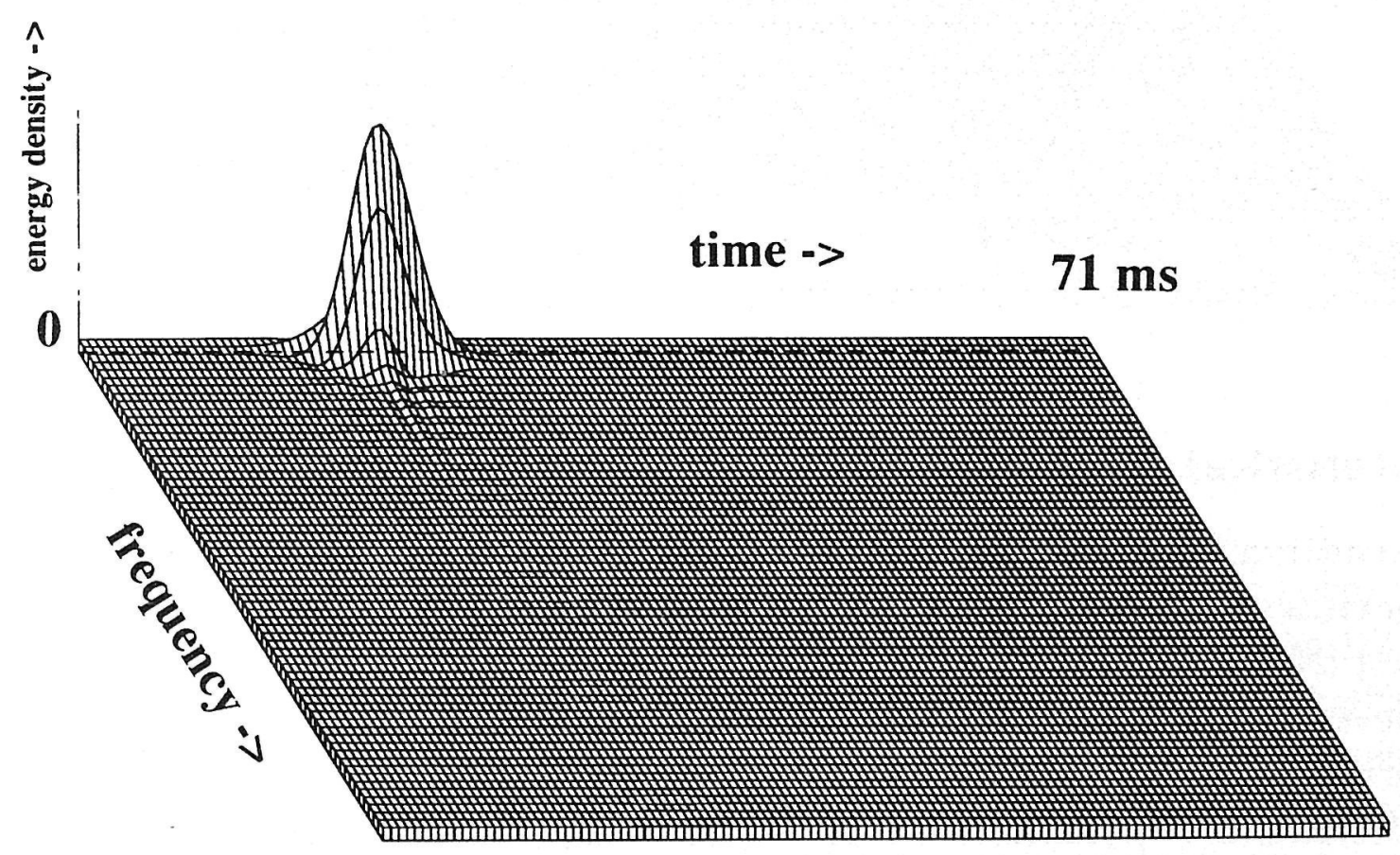

$3600 \mathrm{~Hz}$

* TECA Corp., Pleasantville, NY, U.S.A.

${ }^{\dagger}$ DAS-16F A/D conversion board, $\rightarrow$ Keithley Metrabyte, Taunton, MA, U.S.A. 


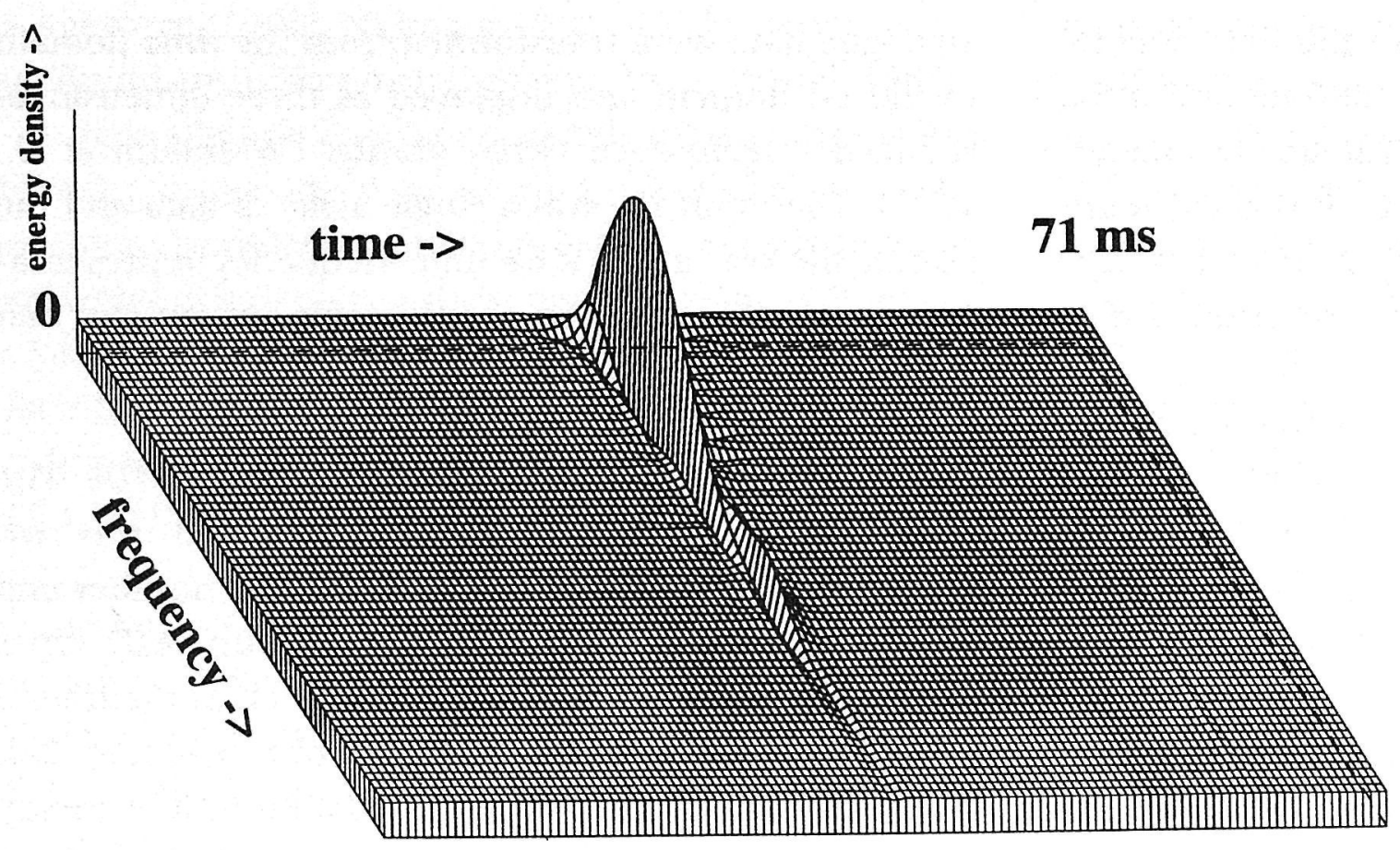

(a)

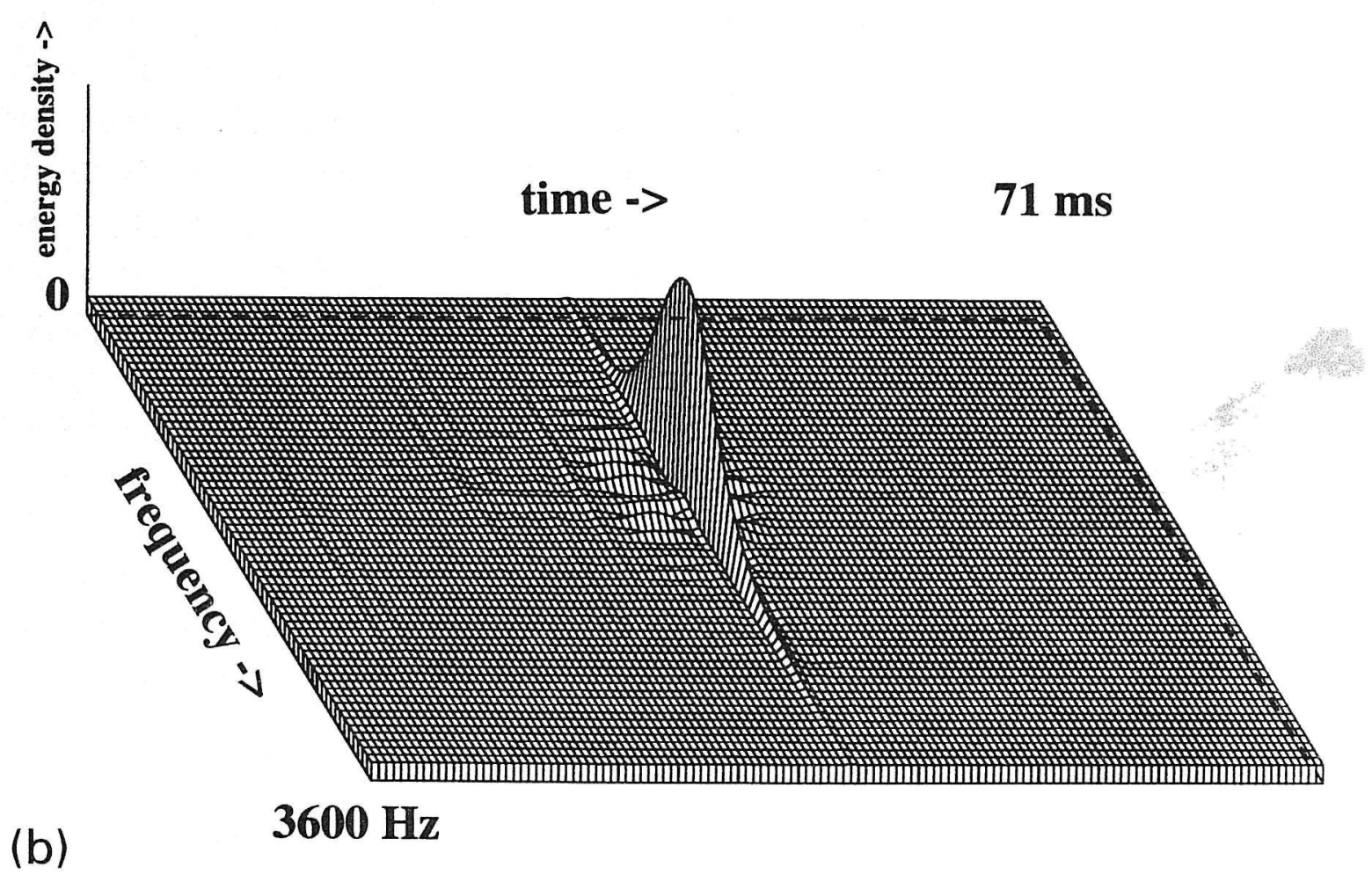

Fig. 2. (a) Clicking RID type 2 with the dominant energy peak in the frequency range, 600$1200 \mathrm{~Hz}$. (b) Clicking, RID type 3, with the energy peak above $1200 \mathrm{~Hz}$.

\section{Statistical methods}

Gender differences between observed and expected frequencies* were tested using Yates corrected Chi-square test (Norusis, 1993) (Table 1). Expected frequency was never less than five in any cell. Cramér's $V$ test was used to measure the strength of association between variables (Norusis, 1990) (Table 2), which is a Chi-square based

\footnotetext{
* Frequency as a statistical term means the number of times an event or item falls into or is expected to fall into a certain class or category. Frequency when used earlier as a physical term means the number of cycles completed by a periodic quantity in a unit time.
}

measure of association that can attain values between 0 and 1 for tables of any dimension. Zero corresponds to no association and 1 to perfect association. The values were calculated using the formula:

$$
V=\sqrt{X^{2} / n(k-1)}
$$

where $k$ is the smaller of the number of rows and columns, $n=$ number of observations and $X^{2}=$ the Pearson Chi-square statistic. The association was to be considered negligible if Cramér's $V$ was less than $0 \cdot 10$, weak if equal to or higher than $0 \cdot 10$ but below $0 \cdot 20$, moderate if equal to or higher than $0 \cdot 20$ but below $0 \cdot 40$, relatively 
Fig. 2. (c) Clicking, RID type 3 , with the energy peak at about $3000 \mathrm{~Hz}$.

Fig. 3. RID type 4 Crepitation with most energy peaks in a low frequency range, $<600 \mathrm{~Hz}$.
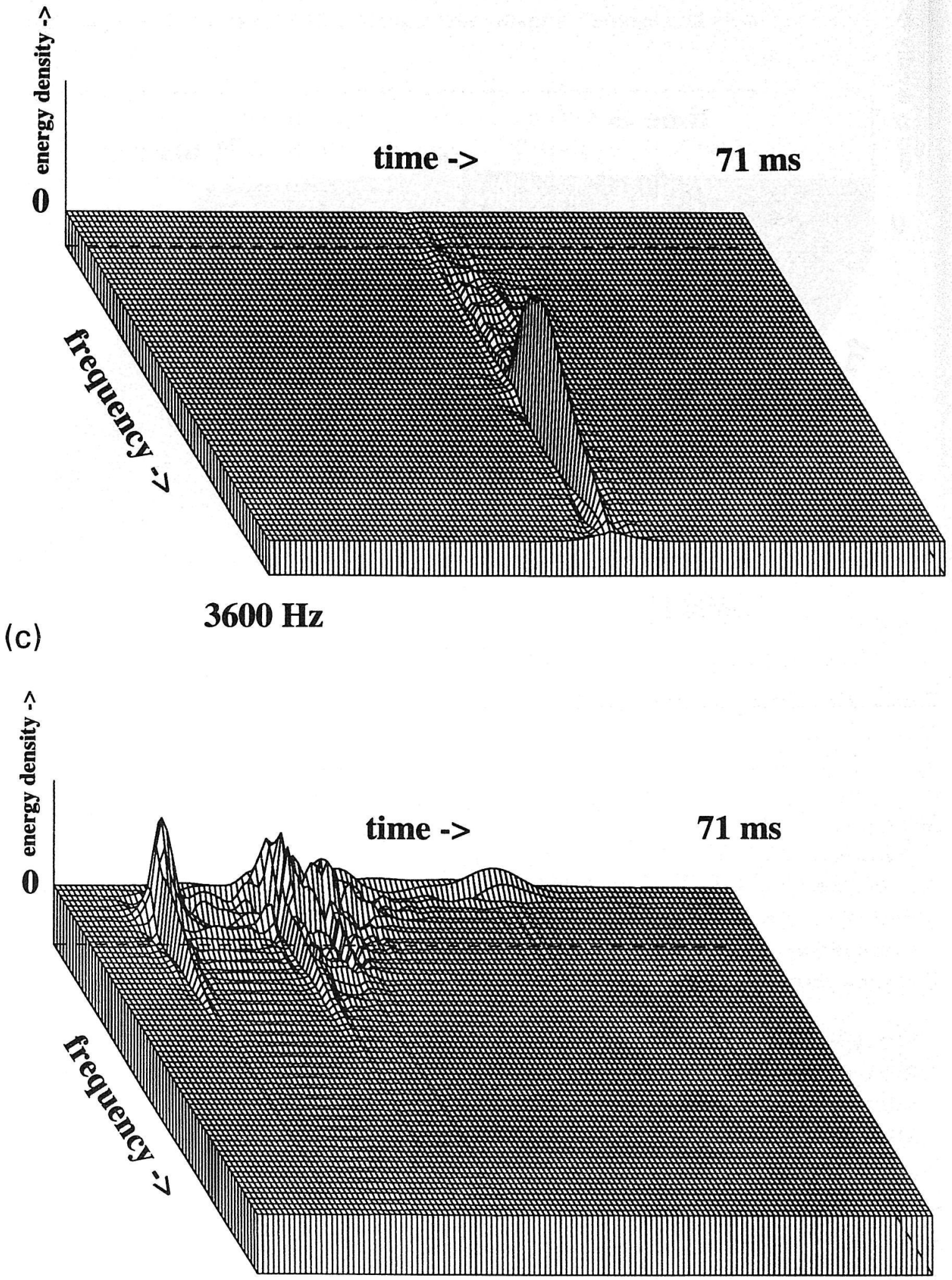

$3600 \mathrm{~Hz}$ strong if equal to or higher than 0.40 but below 0.60 , strong if equal to or higher than 0.60 but below 0.80 and very strong if equal to or above $0 \cdot 80$. Cramér's $V$ rarely achieves a value of 0.80 or above (Poister, 1978; Rea $\delta$ Parker, 1992). The age distributions in the male and female subgroups were compared using the Levene test for evaluating the assumption that the groups came from populations with equal variances (Norusis, 1993). The Independent Samples $t$-test procedure was used to compute Student's $t$ statistic for testing the significance of a difference in age-means for independent samples (Norusis, 1993).

\section{Results}

In completing the questionnaire $29 \cdot 6 \%$ of the subjects admitted to having noises next to their ears, female subjects more often than males $(P<0 \cdot 05)$. With auscultation $40 \cdot 6 \%$ of the subjects were found to have TMJ sounds, $24.0 \%$ of the subjects had clicking, females more often than males $(P<0 \cdot 05)$, and $21 \cdot 1 \%$ had crepitation (Table 1$)$.

Sounds of RID type 1 were found in $45.4 \%$ of the subjects, RID type 2 in $68.0 \%$, RID type 3 in $38.1 \%$, RID type 4 in $49.0 \%$ and RID type 5 in $43.3 \%$. Many subjects had more than one type of sound. RID type 1 was 


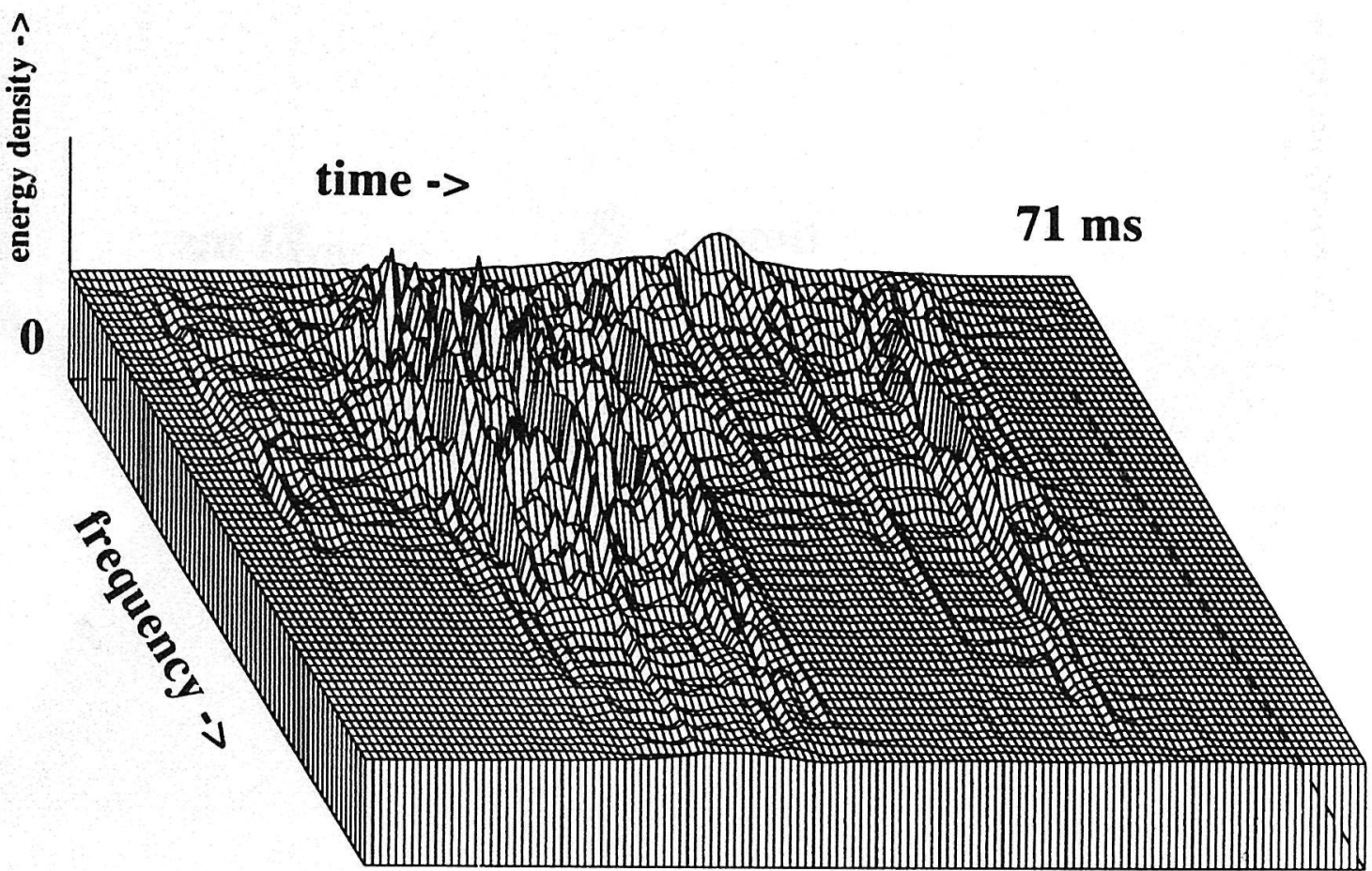

$3600 \mathrm{~Hz}$

\begin{tabular}{|c|c|c|c|c|c|}
\hline & & $\begin{array}{l}\text { Male }(\%) \\
n=38\end{array}$ & $\begin{array}{l}\text { Female }(\%) \\
n=60\end{array}$ & MO & $P$ \\
\hline \multicolumn{6}{|l|}{ Self report } \\
\hline 'Earnoise' & & $18 \cdot 9$ & $41 \cdot 5 *$ & 8 & 0.0240 \\
\hline \multicolumn{6}{|l|}{ Auscultation } \\
\hline Clicking & & $10 \cdot 5$ & $32 \cdot 8^{*}$ & 2 & 0.0126 \\
\hline Crepitation & & $18 \cdot 4$ & $22 \cdot 8$ & 3 & 0.6075 \\
\hline \multicolumn{6}{|c|}{ Electronic recording } \\
\hline & FR & & & & \\
\hline RID type 1 & $<600 \mathrm{~Hz}$ & $28 \cdot 9$ & $55 \cdot 9 * *$ & 1 & 0.0092 \\
\hline RID type 2 & $600-1200 \mathrm{~Hz}$ & $65 \cdot 8$ & $69 \cdot 5$ & 1 & $0 \cdot 7027$ \\
\hline RID type 3 & $>1200 \mathrm{~Hz}$ & $28 \cdot 9$ & $44 \cdot 1$ & 1 & $0 \cdot 1345$ \\
\hline RID type 4 & $<600 \mathrm{~Hz}$ & $36 \cdot 8$ & $56 \cdot 7$ & 0 & 0.0558 \\
\hline RID type 5 & $20-3600 \mathrm{~Hz}$ & $28 \cdot 9$ & $52 \cdot 5 *$ & 1 & 0.0221 \\
\hline
\end{tabular}

MO = number of missing observations; $P=$ probability value for difference between males and females; FR = frequency range where energy peaks were found. 'Earnoise' refers to sounds from the TM joints as reported by the subjects. Cases with missing observations were not included in calculation of percentages. ${ }^{*} P<0.05 ;{ }^{*} P<0.01$. Note that exact $P$ values are also given.
Fig. 4. RID type 5 crepitation with a large number of energy peaks distributed over low, medium and high frequency ranges. The principal difference between clicking and crepitation is most probably that the former occurs at a single impact while the latter occurs when roughened articular surfaces are rubbed against each other.

Table 1. Prevalence of TMJ sounds found to be typical of patients with audible clicking (Table 2). This type was significantly more common in females than in the male subjects $(P<0.01)$. RID type 2 and RID type 3 had similar distributions in males and females (Table 1).

The sounds with multiple energy peaks, RID type 4 and RID type 5, were found to be typical of subjects with crepitation (Table 2 ). RID type 5 was found more often in the female subjects than in the male $(P<0.05)$.
There was also a type of sound (Fig. 5) or artefact not included in the classification schedule that had a very high fundamental frequency associated with a very short temporal period duration, much less than 1 ms. This type of signal, with unclear biological significance, was observed in $38.8 \%$ of the subjects. The energy peaks were at the upper limit of the accelerometers' frequency range. The sampling rate of $7200 \mathrm{~Hz}$ was too low to prevent aliasing in those recordings and the anti-aliasing filter (see 
Table 2. Association between subjects' self report of TMJ sounds, auscultation findings and electronic recordings

\begin{tabular}{|c|c|c|c|c|c|c|}
\hline & $\begin{array}{l}\text { Earnoise } \\
\text { Cramer's } V\end{array}$ & $P$ value & $\begin{array}{l}\text { Clicking } \\
\text { Cramer's } V\end{array}$ & $P$ value & $\begin{array}{l}\text { Crepitation } \\
\text { Cramer's V }\end{array}$ & $P$ value \\
\hline RID type 1 & $0 \cdot 20$ & 0.0620 & $0 \cdot 37 * * *$ & 0.0004 & $0 \cdot 14$ & $0 \cdot 1664$ \\
\hline RID type 2 & 0.03 & 0.7497 & $0 \cdot 17$ & 0.0991 & $0 \cdot 20$ & 0.0539 \\
\hline RID type 3 & 0.08 & 0.4261 & 0.06 & 0.5773 & 0.08 & 0.4181 \\
\hline RID type 4 & $0.23 *$ & 0.0301 & 0.00 & 0.9920 & $0.23^{*}$ & 0.0225 \\
\hline RID type 5 & $0 \cdot 21^{*}$ & 0.0428 & 0.06 & 0.5338 & $0 \cdot 34^{* * *}$ & 0.0009 \\
\hline Earnoise & - & & $0 \cdot 18$ & 0.0847 & $0 \cdot 10$ & 0.3503 \\
\hline
\end{tabular}

Clicking and crepitation were recorded by auscultation using a stethoscope. 'Earnoise' means that the subject admitted to hearing sounds from his/her TM joints. $N=98$. Number of missing observations ranged between 0 and 3 except for earnoise where it was 8 . ${ }^{*} P<0 \cdot 05$; ${ }^{* *} P<0.001$. Note that exact $P$ values (probability for association between column- and row-variable) are also given.

Materials and methods) would have significantly attenuated these signals.

\section{Discussion}

The main result of this study was that electronic recordings could be used to detect and describe distinct differences between TMJ sounds not observed by auscultation. Single event sounds (clicking) could be subdivided into three different types by observing their time-frequency distribution. Such a differentiation may be difficult at least, if possible at all, to perform by auscultation. It was shown that those three types had different gender distribution, which is a good example of how electronic recording of the TMJ sounds can help in identifying sources of variation and thereby increase the possibility to find significant associations. Another important result is that the location of energy peaks differed markedly between the different types of sounds. This means that great variations in audibility should be expected at auscultation (Fig. 6) due to differences in the TMJ sounds' frequency content.

The study confirmed that TMJ sounds are common in a non-patient population (subjects that did not have any subjective need for treatment), and more common in females than in males (Egermark-Eriksson, 1982; Wänman \& Agerberg, 1990; Christensen et al., 1992).
Fig. 5. Clicking with a frequency content so high that the sampling rate $7200 \mathrm{~Hz}$ was too low to avoid aliasing. The net effect of the aliasing is an artefact peak in the high frequency region (about $3000 \mathrm{~Hz}$ ).

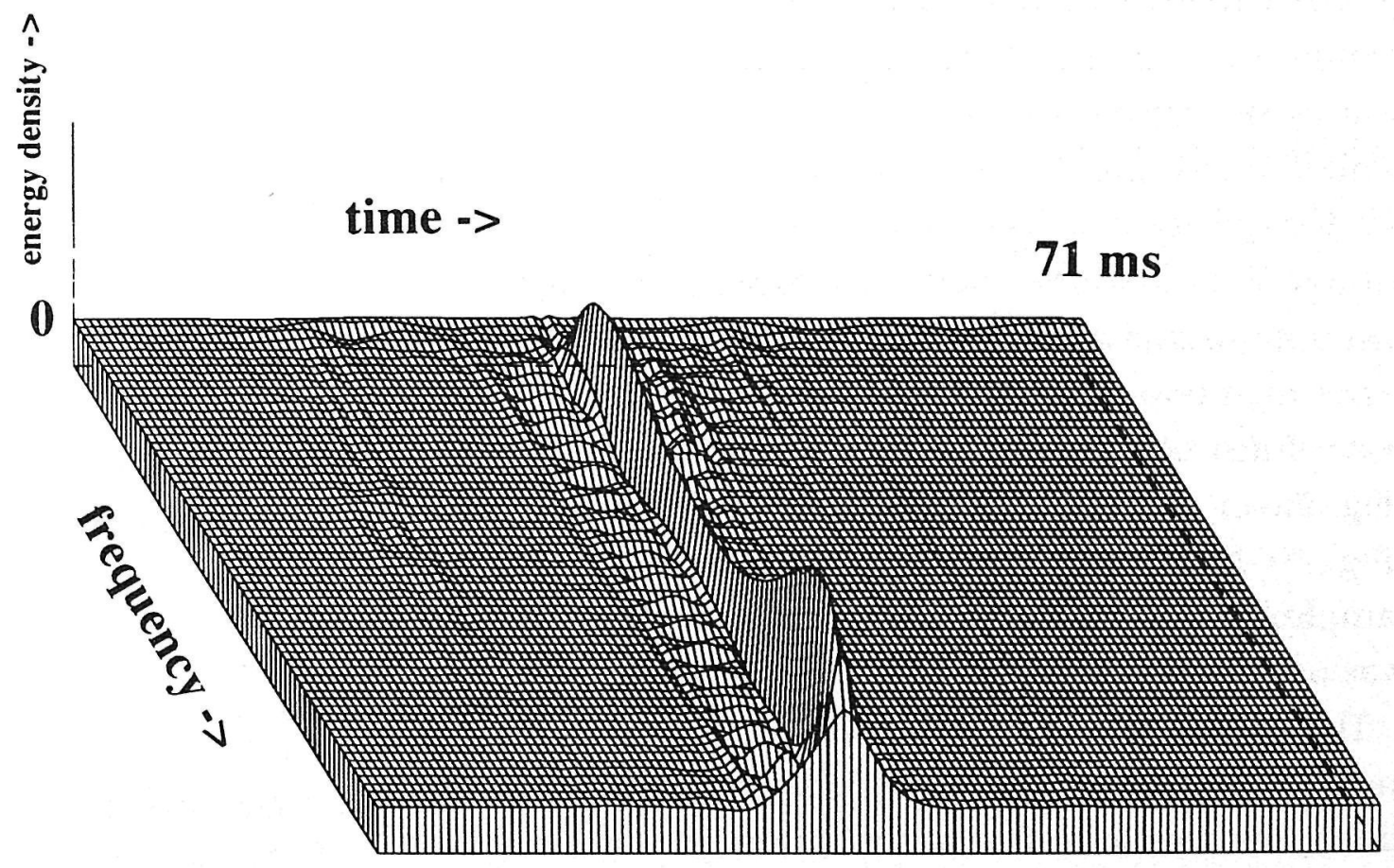

$3600 \mathrm{~Hz}$ 
AREAS OF AUDIBILITY

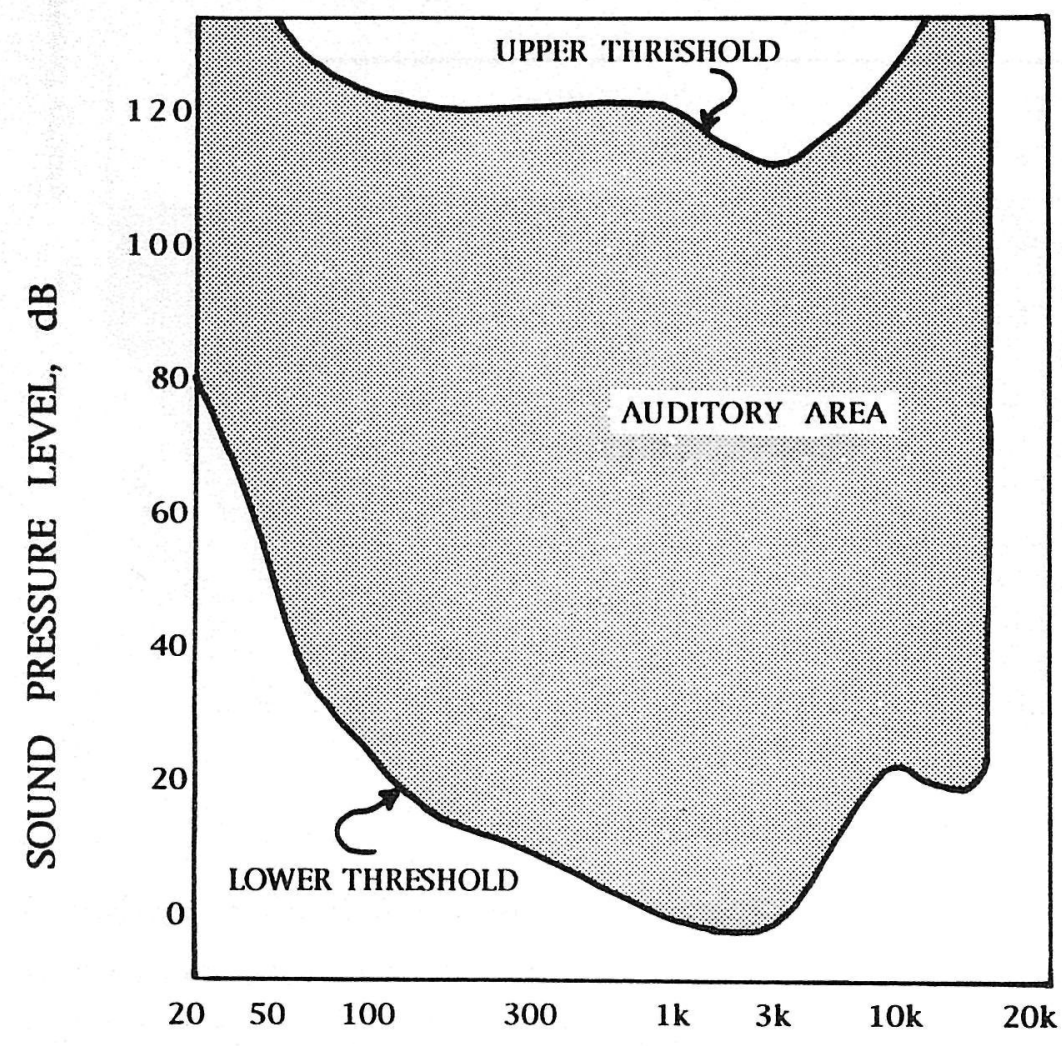

FREQUENCY-HERTZ

Fig. 6. The threshold curves indicate the boundaries of the hearing ability of the human ear. The lower curve shows the lowest level of sound that can be detected and the upper curve indicates where sound is beginning to feel painful. Note the large differences in audibility for sounds in the 20-100 $\mathrm{Hz}$ area as compared to those between 1000 and $3000 \mathrm{~Hz}$. This curve may be very different for different observers while the 'audibility curve' (frequency response) for an accelerometer is flat and possible to calibrate. Adapted from Robinson \& Dadson (1956).

Before sophisticated electronic equipment is used for a systematic collection of sound data in larger subject groups, the sounds, expected ranges in the time domain and in the frequency domain have to be known. The sampling rate and the duration of the time window chosen for spectral analysis have to be in proportion to the duration of the sound event to reduce processing time in computer-aided analysis. Sampling with $1000-2000 \mathrm{~Hz}$ is not high enough to make a true representation of the wave form of sounds like RID type 2 and RID type 3 (Fig. $2 \mathrm{a}-\mathrm{c}$ ). Some of the sounds recorded in this study (Fig. 5) had such high frequency content that the sampling rate has to be higher than the $7200 \mathrm{~Hz}$ that was used in this study.

There were differences between sexes with significantly more females reporting ear-noise than males, and the same difference was found at auscultation and at electronic recording. This could mean that males and females differ in susceptibility to factors causing the sounds. The relationship of joint sound should, therefore, not be studied without a clear separation of the effects on males and females.

Much discussion has been devoted to the question of the prevalence of joint sounds. 'Audible' meaning 'audible at auscultation' is a poor criterion, especially if a stethoscope is not used, because the hearing capability can differ significantly between observers. Nor can observers be calibrated by comparing their findings at auscultation because loudness and other characteristics may not be the same at repeated jaw movements.

The value of TMJ sound recordings has been questioned on the grounds that joint sounds can be recorded from a majority of joints, also from otherwise asymptomatic subjects, with the help of good recording equipment (Pollman, 1980). It is true that the use of advanced methods for amplification and noise reduction may make it possible to record sounds/vibrations from most joints during jaw movement. This is, however, no reason for not using electronic recording if a separation can be made between biological signals for diagnostic interest and noise. The development of such methods should have a high priority because sound recording is relatively simple, not expensive and non-invasive.

\section{Acknowledgments}

The authors express their thanks to Agustin Ifarraguerri for his programming work. This study was supported in part by a grant from the Office of the Vice President of Research, University of Michigan, Ann Arbor, MI. and from the National Science Foundation, NSF grant no. BCS 9110571.

\section{References}

Christensen, L.V., Donegan, S.J. \& McCay, D.C. (1992) Temporomandibular joint vibration analysis in a sample of non-patients. Journal of Craniomandibular Practice, 10, 35.

Drum, R. \& LITT, M. (1987) Spectral analysis of temporomandibular joint sounds. Journal of Prosthetic Dentistry, 58, 485.

Dworkin, S.F., Huggins, K.H., LeResche, L. et al. (1990) Epidemiology of signs and symptoms in temporomandibular disorders: clinical signs in cases and controls. Journal of American Dental Association, 120, 273.

Egermark-Eriksson, I. (1982) Malocclusion and some functional recordings of the masticatory system in Swedish schoolchildren. Swedish Dental Journal, 6, 9.

Ekensten, B. (1952) Phonograms of anomalies of the temporomandibular joint in motion. Odontologisk Tidskrift, 60, 235. 
ERIKSSON, L., WESTESSON, P.L. \& SJÖBERG, H. (1987) Observer performance in describing temporomandibular joint sounds. Journal of Craniomandibular Practice, 5, 32.

ERIKSSON, L., Westesson, P.L. \& Rohlin, M. (1985) Temporomandibular joint sounds in patients with disc displacement. International Journal of Oral Surgery, 14, 428.

FARRAR, W.B. (1972) Differentiation of temporomandibular joint dysfunction to simplify treatment. Journal of Prosthetic Dentistry, 28, 629 .

FARRAR, W.B. \& MCCARTY JR., W.L. (1983) Special Section on Internal Derangements of Disc and Condyle. In: A Clinical Outline of Temporomandibular Joint Diagnosis and Treatment, 7th edn, pp. 53-88. Normandie Publications, Montgomery, Alabama.

Gay, T. \& Bertolami, C.N. (1987) The spectral properties of temporomandibular joint sounds. Journal of Dental Research, 66, 1189.

HFfez, L. \& Blaustein, D. (1986) Advances in sonography of the temporomandibular joint. Oral Surgery, Oral Medicine, Oral Pathology, 62, 486.

Helкimo, M. (1979) Epidemiological Surveys of Dysfunction of the Masticatory System. In: Temporomandibular Joint. Function and Dysfunction. Eds G.A. Zarb \& G.E. Carlsson, p. 175-92. Publ. Munksgaard, Copenhagen.

ISBERG-Holm, A.M. \& Westesson, P.L. (1982a) Movement of disc and condyle in temporomandibular joints with clicking. An arthrographic and cineradiographic study on autopsy specimens. Acta Odontologica Scandinavica, 40, 153.

IsBerg-Holm, A.M. \& Westesson, P.L. (1982b) Movement of disc and condyle in temporomandibular joints with and without clicking. A high-speed cinematographic and dissection study on autopsy specimens. Acta Odontologica Scandinavica, 40, 167.

Ishigaki, S., BessetTe, R.W. \& MARUYAMA, T. (1993) A clinical study of temporomandibular joint (TMJ) vibrations in TMJ dysfunction patients. Journal of Craniomandibular Practice, 11, 7.

KatzBeRG, R.W. \& Westesson, P.L. (1993) Miscellaneous modalities: computed tomography, single photon emission computed tomography, and sound analysis. In: Diagnosis of the Temporomandibular Joint. pp. 223-250. W.B. Saunders Co, Philadelphia.

Michet, C.J. \& Hunder, G.G. (1993) Examination of the joints. In Textbook of Rheumatology. Eds W.N. Kelley, E.D. Harris Jr., S. Ruddy \& C.B. Sledge, p. 351-67. W.B. Saunders, Philadelphia.

Mohl, N.D., Lund, J.P., Widmer, C.G. \& MCCall, W.D. JR. (1990) Devices for the diagnosis and treatment of temporomandibular disorders. Part II: Electromyography and sonography. Journal of Prosthetic Dentistry, 63, 332.

Norusis, M.J. (1990) SPSS/PC + 4.0 Base Manual for the IBM PC/XT/ $A T$ and PS/2. pp. B119-B125. SPSS Inc., Chicago.
NoRusis, M.J. (1993) SPSS ${ }^{R}$ for Windows ${ }^{T M}$ base system user's guide release 6.0. pp. 187, 221-226, 254-263. SPSS Inc., Chicago.

OueLLETTE, P.L. (1974) TMJ sound prints: electronic auscultation and sonographic audiospectral analysis of the temporomandibular joint. Journal of American Dental Association, 89, 623.

Poister, T.H. (1978) Public Program Analysis. p. 443. University Park Press, Baltimore.

Pollman, L. (1980) Sounds produced by the mandibular joint in young men. A mass examination. Journal of Maxillofacial Surgery, 8, 155.

ReA, L.M. \& PARKer, R.A. (1992) Designing and Conducting Survey Research. pp. 202-204. Jossey-Bass Publishers, San Francisco.

Robinson, D.W. \& Dadson, R.S. (1956) A re-determination of the equal-loudness relations for pure tones. British Journal of Applied Physiology, 7, 166.

WÄNMAN, A. \& Agerberg, G. (1990) Temporomandibular joint sounds in adolescents: A longitudinal study. Oral Surgary, Oral Medicine, Oral Pathology, 69, 2.

WATT, D.M. (1963) A preliminary report on the auscultation of the masticatory mechanism. The Dental Practitioner, 14, 27.

WATT, D.M. (1980) Temporomandibular joint sounds. Journal of Dentistry, 8, 119.

WEDEL, A. (1988) Heterogeneity of patients with craniomandibular disorders. Swedish Dental Journal, Suppl. 55.

Widmalm, S.E. \& HEdEGÅRD, B. (1974) An apparatus for the synchronous registration of EMG activity in jaw muscles and of vibrations in the masticatory system. Journal of Oral Rehabilitation, 1, 183.

Widmalm, S.E., Williams, W.J. \& Zheng, C. (1991) Time frequency distributions of TMJ sounds. Journal of Oral Rehabilitation, 18, 403.

Widmalm, S.E., Westesson, P.L., Brooks, S.L., Hatala, M.P. \& PaEsani, D. (1992) Temporomandibular joint sounds: Correlation to joint morphology in fresh autopsy specimens. American Journal of Orthodontics \& Dentofacial Orthopedics, 101, 60.

Widmalm, S.E., GunN, S.M., Christiansen, R.L. \& HaWley, L.M. (1995) Prevalence of signs and symptoms of cranio mandibular disorders and of orofacial parafunction in 4-6 year old African-American and Caucasian children. Journal of Oral Rehabilitation, 22, 87.

WIDMER, C.G. (1989) Temporomandibular joint sounds: a critique of techniques for recording and analysis. Journal of Craniomandibular Practice, 7, 213.

Williams, W.J. \& Jeong, J. (1992) Reduced interference timefrequency distributions. In Time-Frequency Signal Analysis. Methods and Applications. Ed B. Boashash, pp. 74-97. Longman Cheshire, New York.

Correspondence: Dr Sven E. Widmalm, 1565 Kuehnle, Ann Arbor, MI 48103, U.S.A. 
This document is a scanned copy of a printed document. No warranty is given about the accuracy of the copy. Users should refer to the original published version of the material. 